\title{
X-RAY CRYSTALLOGRAPHY ANALYSIS OF COMPOUND LASSBIO-1774 AT ROOM PRESSURE AND AT HIGH PRESSURE
}

\author{
Castro, R. de P. ${ }^{1 *}$; Lima, L. M. ${ }^{2}$; Barreiro, E. J. ${ }^{2}$; Sabino, J. R. ${ }^{1}$ \\ ${ }^{1}$ Instituto de Física, Universidade Federal de Goiás, Goiânia, Goiás, Brasil. \\ ${ }^{2}$ Laboratório de Avaliação e Síntese de Substâncias Bioativas (LASSBio), \\ Universidade Federal do Rio de Janeiro, Rio de Janeiro, Brasil. \\ *rosanepc@posgrad.ufg.br
}

The techniques used in the search for new polymorphs are based, generally, on crystallization in different solvents and under various temperatures. In this work, we explore the variations of pressure as an additional tool in that quest. The compound LASSBio-1774, $\mathrm{C}_{18} \mathrm{H}_{20} \mathrm{~N}_{2} \mathrm{O}_{7}$, is a prototype of hypoglycaemic drug. The single crystals were obtained by slow evaporation method in DMSO. Data collection was performed in the APEX II DUO diffractometer of Bruker $(\mathrm{Mo}-\mathrm{Ka}=0.71073 \AA)$. The unit cell $(\mathrm{a}=15.0319(2) \AA, \mathrm{b}=9.1414(1) \AA, \mathrm{c}=28.9596(4) \AA$, volume $\left.=3979.41(9) \mathrm{A}^{3}\right)$, was obtained based on the refinement of 9969 reflections. The compound crystallized in the PBCA space group. In the following, a single crystal of the compound was subjected to X-ray diffraction data collection at high pressure using a Merrill-Bassett diamond anvil cell. Data collection was performed in the APEX II DUO diffractometer $(\mathrm{Mo}-\mathrm{Ka}=0.71073 \AA$ ). After indexing the data, the following unit cell was obtained: $\mathrm{a}=14.81$ $\AA, \mathrm{b}=9.03 \AA, \mathrm{c}=28.26 \AA, \mathrm{b}=89.78^{\circ}$, volume $=3779 \mathrm{~A}^{3}$. This result showed that there was a transition from the orthorhombic phase to the monoclinic phase besides a reduction of $200 \mathrm{~A}^{3}$ in the unit cell volume. Several attempts to determine the structure were made, but we were unsuccessful. The amount of data has proved insufficient to generate a model for the crystallographic structure of the compound. 